\title{
Return Predictability in Santiago Stock Exchange: an Empirical Analysis Using Portfolio Method
}

\author{
Carlos Elias, Ph.D ${ }^{1}$, Rokas Kirlys, MBA ${ }^{1}$, Kudret Topyan, Ph.D ${ }^{1^{*}}$ \\ ${ }^{1}$ School of Business, Manhattan College, New York City, United States \\ Email: kudret.topyan@manhattan.edu
}

\begin{abstract}
This paper provides a comprehensive analysis on stock return predictability in Santiago Stock Exchange from January 2007 to January 2016 by employing portfolio method. In the riskrelated predictors, we found no statistically significant predictive power of beta, total volatility, and idiosyncratic volatility in all stock sets. In addition to market cap and short-term reversal, the two cheapness variables, book-to-market and cash-flow-to-price ratios showed consistent economically and statistically significant predictive powers in determining the stock returns in the Santiago Stock Exchange. We also found that regrouping the stocks as small and large, low and high book-to-market, beta, and momentum according to the median values adds insights to the analysis. Our results show that the set of large stocks in the exchange is the least predictable set of stocks, however, momentum is efficiently predicted their return. Momentum is significant only for the large stocks and low bookto-market stocks, and risk-related predictors are good for high beta stocks only.
\end{abstract}

Keywords: Santiago stock exchange, stock returns, book-to-market ratio, momentum, stock cheapness, portfolio method

\section{Introduction}

It is widely observed that certain firm-level predictors such as momentum, volatility, book-to-market, and earnings-to-price ratios can effectively predict the equity returns. Through evaluation of the effectiveness of firm level predictors can be viewed in many papers such as Asness, et al. [3], Sapp [44], $\mathrm{Yu}$ [53], and Jiang and Li [34]. As opposed to the risk-based asset pricing models, this type of behavioral models do not explain the predictability using risk factors that are economically meaningful. Instead, they simply investigate the firm-level predictors' relationship with the stock returns and check if they are economically and statistically significant. One widely used method favored by the researchers in evaluating the stock return predictability is the portfolio method ${ }^{1}$. The method is implemented by computing the average periodic portfolio returns sorted by a firm-level predictor for the period in question. The computed average periodic returns then will be evaluated to see if they are statistically and economically significant return predictors. One can list momentum, short-term reversal, market capitalization, beta, total volatility, idiosyncratic volatility, book-to-market ratio, and cash-flow-to-price ratio as commonly evaluated popular firm-level variables. Traditionally, beta, total volatility, and idiosyncratic volatility are grouped as the risk- related predictors while book-to-market and earnings-toprice ratio are grouped as the cheapness-related predictors. Generally, researchers will also form certain subgroups to understand impact of the subgroup characteristics on equity return predictability. One popular subgrouping is small-and-large stocks grouping. Running the analysis just for the small stocks and then just for the large stocks will reveal important insights of size on predictability². With this in mind, we implemented four subgrouping: size, beta, book-to-market, and momentum, using the median values as the benchmarks.

Numerous studies evaluating the firm-level variables' predictive powers in many developed as well as emerging market economies have been around for over two decades. For the U.S. Jagadeesh and Titman's [33] study identifies the market anomalies and provides the researchers with a wealth of information on the predictive powers of many firm-level variables. Fama and French [25], Chan, et al.

\footnotetext{
${ }^{1}$ See Fama EF and J MacBeth [26]

${ }^{2}$ See for example, Chan and Chen $[12]$
} 
[11], Rouwenhorst [42, 43], Grundy and Martin [28], Titman, et al. [47], Wu [49], Arora, Das and Jain [2] and Pincus, et al.[41] evaluated the firm-level predictors for other markets and confirmed that most anomalies of the US financial markets are also observed in markets outside the US. Recently, Cakici and Topyan [8] compiled eight Asian emerging market countries and evaluated the effectiveness of their firmlevel predictors in determining the equity returns.

Campbell R.H. [10] highlights that emerging market returns present a low correlation with developed county returns since emerging market equities have high expected returns possibly associated with larger exposure to risk factors, and emerging market returns are generally more predictable than the developed market returns and it is more likely for the emerging market returns to be influenced by local rather than global information variables.

This paper evaluates the firm-level variables' predictive powers in Chile, a Latin American emerging market economy. We analyzed the data obtained from Santiago Stock Exchange from January 2007 to January 2016. Chile was selected due to its inclusion in almost all common emerging market countries indexes ${ }^{3}$. Possibly due to the lack of firm-level data suitable for the underlined method, it is not common to see similar studies covering Latin American markets. Our search revealed that Chile is the only Latin American country with the workable amount of firm-level data and it is limited to the last 9 years.

Among the few research papers dealing with equity returns in Chile, we have Fuentes et al. [27] analyzing the Chilean Stock market to understand which macroeconomic variables have an effect on the predictability of the stock market using Arbitrage Pricing theory. The study evaluates inflation, growth rate, the percentage change in the price of copper and oil and concludes that studied variables other than inflation do have some effects on stock prices. They also conclude that no arbitrage opportunities exist in the Chilean stock market. Walker, E. [48] evaluates the possibility of predicting future aggregate returns in Chilean stock market using lagged dividend yields and lagged interest rates. The study evaluates the Chilean stock market before and after it was integrated into world markets in 1990 . Walker's work reports that the risk-adjusted lagged dividend yields, lagged interest rates, and dividend/price ratio have explanatory power in predicting the stock returns and that the Chilean market is less predictable before 1990. Espinosa et al. [22] analyze the randomness of the stock indexes for a number of countries in North and South America using standard time series analysis (GARCH and ARMA). The results for Chile reject the randomness and claim a significant amount of predictability in the Chilean market. Their results are similar for all other North and South American stock markets.

The works summarized above, however, are not evaluating the Chilean stock return predictability and its reflections using the portfolio method. By employing the standard portfolio method, one will also discover the similarities and differences in the dynamics of Chile as a Latin American emerging market enabling comparisons with earlier studies covering many other markets around the world.

Specifically, the paper relates the returns on Chilean stocks to eight stock return predictors: size (market capitalization), momentum, short-term reversal, earnings-to-price ratio, book-to-market ratio, total risk, idiosyncratic risk, and beta.

Chile's landmark exchange, the Santiago Stock Exchange was founded on 1893. The exchange has a market capitalization of $\$ 270$ billion plus and is listed as the third largest Latin American stock exchange. In 1973, the Santiago Stock Exchange became a founding member of FIAB, the Latin American Federation of Exchanges. In 1977, IPSA, The Selective Stock Price Index, was created. In 1986, it evolved by new issuances, diversification of instruments, an increase in trading, and the opening of new markets. In 1988, the exchange introduced the electronic trading of stocks and debt instruments. In 1990, trading the Chilean stocks in the international markets was started. In 1991, the Exchange was titled as one of the 33 most important world markets by becoming a member of the WFE, the World Federation of Exchanges. In 2000, the Foreign Market for the public offering and Central Securities Depository (DCV) were initiated. In 2011, with the participation of Chile, Colombia and Peru, MILA, the Latin American Integrated Market began operation. In 2012, the exchange created Exchange Traded Funds (ETFs) and derivatives in Chile. The exchange has continued to expand and evolved into a global point of interest as well as a strategic partner for regional stock markets. Furthermore, Santiago Exchange has prioritized offering new financial instruments, such as ETFs and derivatives. Today, Santiago Exchange

\footnotetext{
${ }^{3}$ Dow Jones, Russell, Bloomberg, S\&P, MCSI, FTSE, IMF, and Columbia University EMPG.
} 
operates with over 250 listed stocks and a trading volume of over USD 2 billion a day in a variety of different financial instruments.

Our results obtained from Santiago Stock Exchange reveal that market capitalization, book-to-market ratio, earnings-to-price ratio, and short-term reversal have considerable predictive power with statistical and economic significance.

However, in the risk-related side, we failed to identify statistically significant predictive power in allstock sets. All three risk-related predictors, total volatility, idiosyncratic volatilities, and the beta showed no predictive power in all stocks set.

Using small and large, low and high book-to-market, low and high beta, and low and high momentum stocks helped us discover important insights that we might otherwise miss. For instance using only highbeta stocks showed statistically and economically significant results for all three risk-related predictors.

Similarly, we discovered that the large stocks are the most difficult to predict but high-beta large stocks and high-momentum large stocks are quite predictable. Momentum turned out to be significant only for low-book-to-market stocks, high- momentum stocks, and large stocks.

The variable descriptions and data are covered in section 2, the methodology of univariate portfoliolevel analysis is covered in section 3, section 4 briefly discusses and reports the results of portfolio methods, and section 5 concludes.

\section{$2 \quad$ Variables and Data}

The data for Chilean stocks is obtained from Morningstar and covers the period from January 2007 through January 2016.

Daily stock returns are used to calculate the total volatility, market beta, and idiosyncratic volatility; monthly returns are used to calculate proxies for momentum and short-term reversals; share prices and shares outstanding are used to calculate market capitalization; the equity book values are used for calculating the book-to-market ratios of individual firms.

The variables used in this work are defined as follows:

(a) Market Capitalization (SIZE): Following the existing literature, firm size is measured by the natural logarithm of the market value of equity (a stock's price times shares outstanding in Pesos) at the end of month $t$ - 1 for each stock.

(b) Beta (BETA): Following Scholes and Williams [45], using the current as well as oneperiod lagged return of the market portfolio in estimating beta:

$$
R_{i, d}-r_{f, d}=\alpha_{i}+\beta_{1, i}\left(R_{m, d-1}-r_{f, d-1}\right)+\beta_{2, t}\left(R_{m, d}-r_{f, d}\right)+\varepsilon_{i, d}
$$

where $R_{i, d}$ is the return on stock $\mathrm{i}$ on day $\mathrm{d}, \mathrm{R}_{\mathrm{m}, \mathrm{d}}$ is the market return on day $\mathrm{d}$, and $\mathrm{r}_{\mathrm{f}, \mathrm{d}}$ is the risk-free rate on day $\mathrm{d}$. Once the above equation is estimated using daily returns within a month, the market beta of stock $\mathrm{i}$ in month $\mathrm{t}$ is defined as $\beta_{i}=\beta_{1, i}+\beta_{2, i}$.

(c) Total Volatility (Stock's Standard Deviation, SD): total volatility of the stock i in month $\mathrm{t}$ is defined as the standard deviation of daily returns within month $\mathrm{t}$ :

$$
S D_{i, t}=\sqrt{\operatorname{var}\left(R_{i, d}\right)}
$$

(d) Stock's Idiosyncratic Volatility (SEE): Monthly idiosyncratic volatility of an individual stock is obtained from the following single factor return generating process:

$$
R_{i, d}-r_{f, d}=\alpha_{i}+\beta_{i}\left(R_{m, d}-r_{f, d}\right)+\varepsilon_{i, d}
$$

where $\varepsilon_{\mathrm{i}, \mathrm{d}}$ is the idiosyncratic return on day $\mathrm{d}$. The idiosyncratic volatility of stock $\mathrm{i}$ in month $\mathrm{t}$ is defined as the standard deviation of daily residuals in month $\mathrm{t}$ :

$$
S S E_{i, t}=\sqrt{\operatorname{var}\left(\varepsilon_{i, d}\right)}
$$

For Beta, SD, and SEE, we use daily stock returns over the past month $(t-1)$, and the values we compute for these measures will be used to forecast stock returns in month $t$.

(e) Short-Term Reversal (STREV): Following Jegadeesh [32] and Lehmann [37], the reversal variable for each stock in month $t$ is defined as the return on the stock over the previous month. (i.e. return in month t-1) 
(f) Momentum (MOM): Following Jegadeesh and Titman [33], the momentum variable for each stock in month $\mathrm{t}$ is defined as the cumulative return from month $\mathrm{t}-12$ to month $\mathrm{t}-2$ (previous 11 months starting one month ago)

(g) Book-to-Market Ratio (BKTM) is calculated by dividing the book value of the stock to the market value of the stock at the point of interest.

(h) Earnings-to-Price (EP) is calculated by dividing the projected earnings per share by the current market price of the stock.

The predictors, total volatility, idiosyncratic volatility, and beta are related to the "riskiness" of the stock while BMKT, and EP are related to "cheapness" of stocks.

\section{Univariate Portfolio-Level Analysis}

The portfolio method computes monthly portfolio returns using the daily stock returns for a given month. The equal-weighted ${ }^{4}$ average monthly stock returns in month $t$ - 1 will be computed and sorted using a firm-level predictor to assess the predictive power for the month $t$. Then, five quintile portfolios will be formed using the predictor of choice: For instance, when we use the market capitalization as the firm-level predictor, we include the stocks with the lowest 20 percent market capitalization in portfolio 1 and the highest 20 percent market capitalization stocks in portfolio 5 using the previous month's data. Then, we compute the present month's average equal-weighted raw returns for those five portfolios. Finally, we subtract the first quintile's (Q1) average stock return from the fifth quintile's (Q5) average stock return to obtain average raw return $\operatorname{spread}^{5}$. This process is repeated for each month we cover. Once all of the average monthly portfolio raw return differences are obtained for the studied period, a value for the entire period is computed by regressing the resulting time-series on an intercept. The regression yields the value and its Newey-West [39] t-statistic ${ }^{6}$ representing the period covered.

In addition to the average raw returns, we also have alphas, the risk-adjusted returns. Alphas are also obtained by regressing the equal weighted portfolio returns on a constant and the excess market returns. Their corresponding Newey-West [39] t-statistics are also reported.

Traditionally, in similar studies, researchers regrouped the data for small and large stocks in an attempt to disclose the size effect. In this study, in addition to regrouping the small and large firms, we regrouped the firms as low and high book-to- market ratio, low and high beta, and finally, low and high momentum firms. With the additional grouping, this work yields a more comprehensive analysis of the firm-level predictors: the readers will be able to see the power of the firm-level predictors in a number of controlled environments. In other words, in addition to controlling the market capitalization, the readers will now see the results when book-to-market, momentum, and beta are controlled.

Our findings are tabulated using the sorting predictor as the table name. For instance, Table 1. Market Capitalization, reports the raw return differences of the first and fifth portfolios when the returns are sorted using the market cap, but at the same time, it regroups the returns of low and high book-to-market stocks using the median value, sorts them using the size, and reports the return differences of first and third ${ }^{7}$ portfolios. As we move to the right on the table, we see the same for beta and momentum. This procedure helped us to discover the significant predictive powers not noticeable when ungrouped data is used. For instance, momentum is not statistically significant when we apply the portfolio method to all stocks set; however, it is significant, in large stocks (when the size is controlled) and low book-to-market stocks (when the book-to-market is controlled). Similarly, the beta, the idiosyncratic volatility, and the total volatility are economically and statistically significant only for the high-beta stocks.

The procedure also helped us to understand the symmetry around the median values for size, beta,

\footnotetext{
${ }^{4}$ We also have the results obtained using the value weighted index, but did not report them due to the similarities in results as well as keeping our work more consistent with the previous studies.

${ }^{5}$ This is equivalent of shorting the lowest return portfolio and going long on the highest return one, obtaining the return difference mentioned.

${ }^{6}$ Throughout this paper, t-value means Newey-West [39] t-statistic.

${ }^{7}$ Due to the lack of sufficient data, when we regrouped the numbers using the median value, we sorted them into terciles and evaluated the return differences of the first and third terciles.
} 
momentum, and book-to-market ratio. For instance, the book-to- market ratio is not a good predictor for large stock but a very powerful one for the small ones, and not a good one for low-book-to-market firms, but a very good one for high- book-to-market ones. Earnings-to-price ratio is not predicting the equity returns when used with low-momentum firms or high-beta firms but a very good one when used with high-momentum or low-beta ones.

\section{The Effectiveness of Firm-Level Returns Predictors}

Tables 1 through 8 report the effectiveness of firm-level return predictors in two distinct categories: Raw return differences and risk-adjusted return differences (alphas). For all stocks sets, raw return differences of the first (the lowest returns) and fifth (the highest returns) portfolios and alphas, the risk-adjusted returns, and for the regrouped sets, raw return differences of the first (the lowest return) and third (the highest return) portfolios and alphas, the risk-adjusted returns are reported. Regrouping has been performed in four categories: The market capitalization, book-to-market ratios, beta, and momentum. In this section, stocks are regrouped using their firm-level predictor values. For instance, once the stocks are sorted using their market capitalization, we used the median market capitalization value to create small and large stock sets. Then, we performed the same portfolio method to two distinct sets to see if the results are affected by the market capitalization.

\subsection{Market Capitalization}

Size effect in finance is strong and almost always statistically and economically significant. Size effect refers to the observation that smaller firms have higher returns than the larger ones, on the average, over the long horizons. As a result, one may consider the firm size as a proxy for the risk: Smaller firms, in general, are much more risky, compared to larger firms, leading to lower prices and higher returns ${ }^{8}$. On the other hand, Liu [38] argued that the stocks of smaller firms are less liquid and therefore investors require higher returns as a compensation for the liquidity risk.

Table 1. Market capitalization. All-stocks column reports the equal-weighted portfolio quintile returns formed monthly from January 2007 to January 2016, sorted into quintiles based on market cap. Q5 is the portfolio of stocks with the highest quintile of market cap. Rest of the table report the return differences of portfolio terciles (q3 is the highest tercile) formed monthly for other subcategories. Returns and alpha spreads and their Newey-West [39] tstatistics are reported with $5 \%$ or higher significance in boldface. BETA is computed using daily returns over the past month.

\begin{tabular}{|c|c|c|c|c|c|c|c|c|c|}
\hline \multirow{2}{*}{$\begin{array}{l}\text { Sorted by Market } \\
\text { Cap }\end{array}$} & \multirow{2}{*}{ All stocks } & \multicolumn{2}{|l|}{ Size } & \multicolumn{2}{|c|}{ Book-to-Market } & \multicolumn{2}{|l|}{ Beta } & \multicolumn{2}{|c|}{ Momentum } \\
\hline & & Small & Large & Low & High & Low & High & Low & High \\
\hline q1/Q1 & $2.51 \%$ & $2.50 \%$ & $0.60 \%$ & $0.27 \%$ & $2.23 \%$ & $1.50 \%$ & $3.32 \%$ & $1.43 \%$ & $2.95 \%$ \\
\hline q2/Q2 & $1.82 \%$ & $1.93 \%$ & $0.58 \%$ & $0.03 \%$ & $85 \%$ & $0.16 \%$ & $0.55 \%$ & $0.15 \%$ & $1.19 \%$ \\
\hline q3/Q3 & $0.19 \%$ & $0.29 \%$ & $0.06 \%$ & $0.21 \%$ & $0.61 \%$ & $0.02 \%$ & $0.66 \%$ & $-0.07 \%$ & $1.03 \%$ \\
\hline Q4 & $0.59 \%$ & & & & & & & & \\
\hline Q5 & $0.06 \%$ & & & & & & & & \\
\hline $\bar{q}$ q-q1/Q5-Q1 & $-2.45 \%$ & $-2.27 \%$ & $-0.50 \%$ & $-0.01 \%$ & $-1.66 \%$ & $-1.49 \%$ & $-2.68 \%$ & $-1.56 \%$ & $-1.87 \%$ \\
\hline t-stat & -3.74 & -3.45 & -1.38 & -0.03 & -2.65 & -2.82 & -2.21 & -2.01 & -2.02 \\
\hline alpha & $-2.54 \%$ & $-2.50 \%$ & $-0.28 \%$ & $0.11 \%$ & $-1.79 \%$ & $-1.45 \%$ & $-1.68 \%$ & $-1.28 \%$ & $-1.29 \%$ \\
\hline t-stat & -3.86 & -3.72 & -0.80 & 0.34 & -2.74 & -2.75 & -1.49 & -1.65 & -1.43 \\
\hline
\end{tabular}

Table 1 uses the size to sort the returns. Q1 is the all-stocks portfolio with the lowest relative size, and their equal-weighted average monthly returns and Q5 is the same for the highest relative firm sizes. All stocks column of Table 1 reports average raw return difference between quintile 5 and quintile 1 (Q5 Q1) and is equal to $-2.45 \%$ per month with a corresponding t-statistic of -3.74 . The difference in risk-

\footnotetext{
${ }^{8}$ See for example Crain [18]
} 
adjusted raw returns, alpha, is $-2.54 \%$ with a corresponding t-statistic of -3.86 . Both of these values present good economic and statistical significance.

We then regrouped the stocks as small and large stocks, low book-to-market and high book-to-market stocks, low-beta and high-beta stocks, and finally, low- momentum and high-momentum stocks by using the corresponding median values. This process is a standard procedure implemented to control certain attributes. Since the number of stocks included in those sets is limited, we formed only 3 portfolios including $1 / 3$ of the stocks in each, in such a way that $q 1$ is a small stocks portfolio with the lowest relative size of their corresponding average monthly returns, and q3 is the same for the highest firm size, and $\mathrm{q} 3-\mathrm{q} 1$ is the return difference of the portfolios. We performed the same analysis to the subsets to see if we obtain more information using more homogeneous set. When we apply the portfolio method to, say, small stocks only, it implies that the results are obtained by controlling the size, and so on. As we can see from the size section of Table 1, raw return and the risk-adjusted return differences are significant, statistically and economically, for the small stocks but not for the large ones. High book-tomarket stocks, when sorted by size, yields $-1.66 \%$ raw return difference with a t-value of -2.65 , and $-1.79 \%$ risk-adjusted return differences with a t-value of -2.74 . We do not have statistical significance in the low book-to-market stocks return differences. On the beta side, when low-beta stocks are sorted by the firm size, we have economically and statistically significant coefficients for both risk-adjusted and row returns: The difference in row returns is -1.49 percent with a t-statistic of -2.82 while the difference in riskadjusted returns is -1.45 with a t-value of -2.75 . For high-beta stocks, raw return difference increases with a value of -2.68 percent, however, the t-statistic value is now -2.21 . Risk-adjusted alpha value is 1.685 but the t-statistic value is only -1.49 . In summary, the raw return difference is twice as visible in high beta stocks, but statistical significance declines a bit. Finally, when stocks are classified as low and high momentum stocks and then sorted by the size, we obtained -1.56 percent and -1.87 percent row return differences with t-statistic values of -2.01 and -2.02 , respectively, implying a slightly higher economic significance in high-momentum stocks. The alphas for the same were -1.28 and -1.29 with Newey-West [39] t-statistic values of -1.61 and -1.43 . Those results are very much in line with the effectiveness of market cap as an equity return predictor in many emerging markets studied by the researchers, as Cakici and Topyan [8] disclose the same for 8 Asian emerging markets. In their book, they showed that size was effective for all groups except for the large-stocks and low-book-to- market stocks.

\subsection{Book-to-Market Ratio}

This well-documented effect is also called as the value effect: In general, high book-to-market stocks, also called value stocks, earn a significant positive excess return, while low-book-to-market stocks, also called growth stocks, earn a significant negative excess return. The source of the effect, however, is attributed to unobserved risk factors by Fama and French [24] while it was tied to mispricing by Lakonishok, Shleifer, and Vishny [36]. In addition, it is argued by Chen and Zhang [14] that in an expanding economy, the risk premium is smaller since high book-to-market stocks are not much riskier than low book-to-market stocks.

Table 2 reports results obtained by sorting the returns using book-to-market ratio. Q1 is the portfolio that reports the equal-weighted average monthly return of all stocks with the lowest quintile of book-tomarket ratios while Q5 is the same for the highest book-to-market stocks. All stocks column of Table 2, therefore, reports the difference in equal-weighted average raw returns between the extreme quintiles (Q5 - Q1) and its value is $1.72 \%$ per month with a t-value of 3.29 . The difference in risk-adjusted raw returns, alpha, is $1.37 \%$ with a corresponding t-statistic of 2.61. Both values present good economic and statistical significance. Expectedly, this section confirms the positive relationship between book-to-market and return differences showing higher return differences for higher book-to-market stocks. Santiago Stock Exchange, however, presents somewhat weak predictive power for book-to-market compared to the rest of the world. Almost all previous studies agree that book-to-market ratio is possibly the most important and consistent firm-level predictor for the rest of the world! 
Table 2. Book-to-market ratio. All-stocks column reports the equal-weighted portfolio quintile returns formed monthly from January 2007 to January 2016, sorted into quintiles based on book-to-market ratio. Q1 is the portfolio of stocks with the highest quintile of book-to-market ratio. Rest of the table report the return differences of portfolio terciles ( $\mathrm{q} 1$ is the highest terciles) formed monthly for other subcategories. Return and alpha spreads and their Newey-West [39] t-statistics are reported with $5 \%$ or higher significance in boldface. BETA is computed using daily returns over the past month.

\begin{tabular}{|c|c|c|c|c|c|c|c|c|c|}
\hline \multirow[t]{2}{*}{ Sorted by BKTM } & \multirow[t]{2}{*}{ All stocks } & \multicolumn{2}{|l|}{ Size } & \multicolumn{2}{|c|}{ Book-to-Market } & \multicolumn{2}{|l|}{ Beta } & \multicolumn{2}{|c|}{ Momentum } \\
\hline & & Small & Large & Low & High & Low & High & Low & High \\
\hline q1/Q1 & $0.33 \%$ & $0.25 \%$ & $0.21 \%$ & $0.34 \%$ & $0.59 \%$ & $0.35 \%$ & $0.42 \%$ & $-0.20 \%$ & $0.59 \%$ \\
\hline $\mathrm{q} 2 / \mathrm{Q} 2$ & $-0.01 \%$ & $1.12 \%$ & $0.18 \%$ & $0.23 \%$ & $0.82 \%$ & $1.02 \%$ & $0.66 \%$ & $0.71 \%$ & $1.08 \%$ \\
\hline q3/Q3 & $0.23 \%$ & $2.21 \%$ & $0.30 \%$ & $-0.07 \%$ & $2.25 \%$ & $1.23 \%$ & $0.93 \%$ & $1.36 \%$ & $1.33 \%$ \\
\hline Q4 & $0.58 \%$ & & & & & & & & \\
\hline Q5 & $2.06 \%$ & & & & & & & & \\
\hline q3-q1/Q5-Q1 & $1.72 \%$ & $2.07 \%$ & $0.10 \%$ & $-0.41 \%$ & $1.78 \%$ & $0.91 \%$ & $0.52 \%$ & $1.60 \%$ & $0.79 \%$ \\
\hline t-stat & 3.29 & 3.45 & 0.41 & -1.44 & 2.84 & 1.67 & 1.24 & 3.28 & 2.68 \\
\hline alpha & $1.37 \%$ & $1.74 \%$ & $0.11 \%$ & $-0.43 \%$ & $1.77 \%$ & $0.94 \%$ & $0.50 \%$ & $1.59 \%$ & $0.88 \%$ \\
\hline t-stat & 2.61 & 2.89 & 0.44 & -1.51 & 2.80 & 1.74 & 1.18 & 3.24 & 3.17 \\
\hline
\end{tabular}

When we performed the analysis to small stocks, we obtained economically significant raw and riskadjusted return differences of $2.07 \%$ and $1.74 \%$ with the t-values values of 3.45 and 2.89 , respectively. Large stocks set did not present any statistically significant predictive powers, implying that the bookto-market sorting is dominantly a small stock phenomenon. On the book-to-market front, high book-tomarket stocks show a positive relationship with return differences with proper statistical and economic significance, while low book-to-market set yields a negative sign and no statistical significance. Row return difference for high book-to-market stocks is $1.78 \%$ with a t-statistic of 2.84 . This is to note that book-to-market ratio has high predictive power in high-book-to-market stocks set.

High and low-beta stocks return differences were not statistically significant. Momentum, on the other hand, presented statistically and economically significant results. Low momentum stocks, when sorted with book-to-market ratio yield $1.6 \%$ return difference with t-statistic of 3.28 while the alpha is $1.59 \%$ with a t-statistic of 3.24. High momentum stocks, however, show only $0.79 \%$ raw-return difference with a t-statistic of 2.68 and $0.88 \%$ risk-adjusted return difference with a t-value of 3.17 . The level of economic significance implies that the book-to-market sorting is twice as important in low-momentum stocks compared to the high-momentum ones. In summary, the book-to- market ratio has a reliably positive impact on expected returns of small-stocks, and high-book-to-market stocks, as well as low and high momentum stocks. Large-stocks and low- book-to-market stocks, and low or high-beta stocks do not present any statistical significance. This is important since Cakici and Topyan [8] reported across to board significance for book-to-market for all eight Asian emerging markets confirming the long consistency of book-to-market as a best known return predictor almost everywhere and in any subgroup. Researchers should look into this issue in detail to understand the possible reasons of this diversion from the literature.

\subsection{Earnings-to-Price Ratio}

In order to test the predictability of earnings capitalization rate, we use the inverse of price-earnings ratio, also called as earnings yield. This is a rate that investors will use to capitalize a firm's next period's expected earnings. A lower E/P ratio implies higher growth in earnings. Like most studies on US market (e.g. Cochrane [16], Campbell and Shiller [9], Fama and French [23], Kothari and Shanken [35]) there exists a statistically and economically significant predictive power of EP ratio in the Chilean market. Furthermore, these results are in line with the Japanese market as highlighted by Chan, Hamao, and Lakonishok [13]. 
Table 3. Earnings-to-price ratio. All-stocks column reports the equal-weighted portfolio quintile returns formed monthly from January 2007 to January 2016, sorted into quintiles based on earnings-to-price ratio. Q1 is the portfolio of stocks with the highest quintile of earnings-to-price ratio. Rest of the table report the return differences of portfolio terciles (q1 is the highest terciles) formed monthly for other subcategories. Return and alpha spreads and their Newey-West [39] t-statistics are reported with $5 \%$ or higher significance in boldface. BETA is computed using daily returns over the past month.

\begin{tabular}{|c|c|c|c|c|c|c|c|c|c|}
\hline \multirow[t]{2}{*}{ Sorted by EP } & \multirow[t]{2}{*}{ All stocks } & \multicolumn{2}{|l|}{ Size } & \multicolumn{2}{|c|}{ Book-to-Market } & \multicolumn{2}{|l|}{ Beta } & \multicolumn{2}{|c|}{ Momentum } \\
\hline & & Small & Large & Low & High & Low & High & Low & High \\
\hline q1/Q1 & $0.23 \%$ & $0.51 \%$ & $0.23 \%$ & $-0.22 \%$ & $0.76 \%$ & $0.09 \%$ & $0.47 \%$ & $-0.07 \%$ & $0.56 \%$ \\
\hline q2/Q2 & $-0.10 \%$ & $1.16 \%$ & $0.38 \%$ & $0.30 \%$ & $0.54 \%$ & $1.20 \%$ & $0.56 \%$ & $0.55 \%$ & $1.25 \%$ \\
\hline q3/Q3 & $0.59 \%$ & $1.85 \%$ & $0.48 \%$ & $0.47 \%$ & $1.91 \%$ & $1.29 \%$ & $0.79 \%$ & $0.67 \%$ & $1.37 \%$ \\
\hline Q4 & $0.49 \%$ & & & & & & & & \\
\hline Q5 & $1.81 \%$ & & & & & & & & \\
\hline q3-q1/Q5-Q1 & $1.58 \%$ & $1.41 \%$ & $0.28 \%$ & $0.72 \%$ & $1.18 \%$ & $1.22 \%$ & $0.36 \%$ & $0.77 \%$ & $0.80 \%$ \\
\hline t-stat & 2.34 & 2.69 & 1.10 & 2.53 & 2.08 & 2.30 & 1.23 & 1.75 & 2.04 \\
\hline alpha & $1.21 \%$ & $1.04 \%$ & $0.31 \%$ & $0.79 \%$ & $1.06 \%$ & $1.21 \%$ & $0.40 \%$ & $0.75 \%$ & $0.79 \%$ \\
\hline t-stat & 1.79 & 2.00 & 1.21 & 2.89 & 1.97 & 2.25 & 1.35 & 1.68 & 2.09 \\
\hline
\end{tabular}

In more detail, Table 3 uses earnings-to-price ratio as the sorting predictor, and all stocks column of Table 3 reports the average equal-weighted raw return difference between extreme quintiles (Q5 - Q1) and is equal to $1.58 \%$ per month with a t-value of 2.34 . The difference in risk-adjusted raw returns, alpha, is $1.21 \%$ with a corresponding t- value of 1.79 . For the small stocks set, those numbers are $1.41 \%$ with a t-statistic of 2.69 and $1.04 \%$ with a t-statistic of 2.00 . In line with the previous studies, we do not have statistically significant values for large stocks. High and low book-to-market grouping produced similar statistical significance with t-value of 2.53 and 2.08 for the high and low sets, while the coefficient values are 0.72 and 1.18, respectively. Alpha values showed similar tendencies with 0.79 and 1.06 values and tstatistic of 2.89 and 1.97, for the low and high sets, respectively. The results imply that earnings-to-price sorting looks symmetric for low and high book-to-market stocks. Beta grouping shows statistical significance only for the low-beta set: the raw return difference is $1.29 \%$ for the low- beta set with a tstatistic of 2.30 and $1.21 \%$ for the alpha with a t-statistic of 2.25 . On the momentum side, we have statistical significance in high-momentum stocks only. The raw return difference for the high-momentum stocks is $0.8 \%$ with t-value of 2.04 and alpha is $0.79 \%$ with a t-value of 2.09 .

\subsection{Total Volatility}

Total volatility is an important risk indicator for securities held in isolation, but it is irrelevant for stocks included in well-diversified portfolios. However, the information contained in total volatility is still considered as important. When other things held constant, the higher is the standard deviation of a stock, the higher is the value of its beta ${ }^{9}$. This conditional positive relationship between the total volatility and beta is not very simple: a low beta will not necessarily imply that the total volatility is also low. In other words, a stock may have high volatility and low correlation, producing a low beta.

Table 4 shows that when stocks are ranked using total volatility, there exist a $1.87 \%$ monthly return difference with a t-value of 1.65. This is not statistically significant at the usual $5 \%$ level, however, it has an economic significance level one should not ignore. Risk-adjusted alpha has no economic or statistical significance. When sub- grouped, we see $2.83 \%$ return difference with a t-value of 2.10 in the set of high-beta stocks. Other sub-groups show no statistical significance at the usual $5 \%$ level. We have some noticeable economic and statistical significance for the sets of small stocks and high-momentum stocks.

\footnotetext{
${ }^{9}$ Since $\beta \mathrm{a}=\rho \sigma_{\mathrm{a}} / \sigma_{\mathrm{m}}$ where $\rho$ is the correlation between rates of returns and $\sigma_{\mathrm{a}}$ and $\sigma \mathrm{m}$ are total volatilities of the stock $\boldsymbol{a}$ and market, respectively.
} 
Table 4. Total volatility. All-stocks column reports the equal-weighted portfolio quintile returns formed monthly from January 2007 to January 2016, sorted into quintiles based on total volatility. Q1 is the portfolio of stocks with the highest quintile of total volatility. Rest of the table report the return differences of portfolio terciles ( $\mathrm{q} 1$ is the highest terciles) formed monthly for other subcategories. Return and alpha spreads and their Newey-West [39] tstatistics are reported with $5 \%$ or higher significance in boldface. Beta and total volatility are computed using daily returns over the past month.

\begin{tabular}{|c|c|c|c|c|c|c|c|c|c|}
\hline \multirow[t]{2}{*}{ Sorted by SD } & \multirow[t]{2}{*}{ All stocks } & \multicolumn{2}{|l|}{ Size } & \multicolumn{2}{|c|}{ Book-to-Market } & \multicolumn{2}{|l|}{ Beta } & \multicolumn{2}{|c|}{ Momentum } \\
\hline & & Small & Large & Low & High & Low & High & Low & High \\
\hline q1/Q1 & $1.14 \%$ & $1.06 \%$ & $0.22 \%$ & $0.37 \%$ & $0.85 \%$ & $1.41 \%$ & $0.61 \%$ & $0.49 \%$ & $0.91 \%$ \\
\hline q2/Q2 & $0.69 \%$ & $1.73 \%$ & $0.27 \%$ & $0.56 \%$ & $0.59 \%$ & $1.43 \%$ & $0.33 \%$ & $1.16 \%$ & $0.67 \%$ \\
\hline q3/Q3 & $1.24 \%$ & $2.23 \%$ & $0.42 \%$ & $0.20 \%$ & $0.95 \%$ & $0.58 \%$ & $3.42 \%$ & $1.07 \%$ & $2.37 \%$ \\
\hline Q4 & $0.19 \%$ & & & & & & & & \\
\hline Q5 & $3.01 \%$ & & & & & & & & \\
\hline q3-q1/Q5-Q1 & $1.87 \%$ & $1.12 \%$ & $0.21 \%$ & $-0.20 \%$ & $0.03 \%$ & $-0.87 \%$ & $2.83 \%$ & $0.56 \%$ & $1.45 \%$ \\
\hline t-stat & 1.65 & 1.53 & 0.60 & -0.67 & 0.05 & -1.07 & 2.10 & 0.73 & 1.48 \\
\hline alpha & $0.50 \%$ & $-0.02 \%$ & $0.04 \%$ & $-0.47 \%$ & $-0.21 \%$ & $-0.63 \%$ & $1.36 \%$ & $-0.34 \%$ & $0.50 \%$ \\
\hline t-stat & 0.47 & -0.02 & 0.11 & -1.66 & -0.40 & -0.77 & 1.12 & -0.52 & 0.53 \\
\hline
\end{tabular}

\subsection{Beta, Beta Anomaly, and Lottery-Like Stocks}

On the beta front, the relevant question is if we use the stock's beta to explain future stock returns can we obtain statistically and economically significant results? Evidently, there is no sure answer to this question as financial economists have investigated how beta is associated with equity returns for many decades but could not reach to a consensus on the issue. In addition, the stability of beta coefficient has also long been an important question for researchers as it relates to the reliability of beta in return projections.

Theoretically, it is expected that portfolios formed with high-beta stocks should yield positive abnormal returns while portfolios formed with low-beta stocks should yield negative abnormal returns. However, behavioral models often produce conflicting results. Bali et al. [7] define the beta anomaly as positive (negative) abnormal returns of portfolios comprised of low-beta (high-beta) stocks and highlight it as one of the most persistent and widely studied anomalies in empirical research of security returns. Their paper demonstrates that investors' demand for lottery-like stocks is an important driver of the beta anomaly. Since lottery-like stock investors generate demand for stocks with high probabilities of large short-term up price jumps and those jumps are partially caused by a stock's sensitivity to the overall market. High (low) lottery demand-based price pressure exerted on high-beta (low-beta) stocks pushes the prices of such stocks up (down) causing decreasing (increasing) future returns.

Bali et al. [7] suggest that the beta anomaly is a manifestation of the effect of lottery demand on stock returns. They show that on average, lottery demand price pressure falls mostly on high-beta stocks, since lottery demand and beta are positively correlated in the cross section, creating a strong betaanomaly. However, when lottery demand price pressure is not disproportionately exerted on high-beta stocks, the returns associated with the beta anomaly are very low or nonexistent. Table $\mathbf{5}$ summarizes our results and shows that there is no beta anomaly in Santiago Stock Exchange as low-beta stocks produce positive but low return difference with no statistical significance while high-beta stocks yield $2.73 \%$ monthly return difference with proper statistical significance at $5 \%$ level. As we pointed out before, there exist a remarkable similarity in the results of raking with beta (Table 5) and ranking with total volatility (Table 4), in terms of economic and statistical significance.

Furthermore, following Bali et al. [6], in an attempt to test the impact of investors' demand for lottery-like stocks, we generated two proxies of lottery demand, MAX(1) and MAX(5), defined as the maximum daily return over the past one month, and average of the highest five daily returns over the past one month, respectively, and formed uniformed portfolios based on MAX(1) and MAX(5). We used the results to compare if lottery demand, identified in the US equity market and that explains both idiosyncratic volatility and beta puzzles, is significant in the cross-section of individual stocks trading in the Chilean equity market. 
Table 5. Beta. All-stocks column reports the equal-weighted portfolio quintile returns formed monthly from January 2007 to January 2016, sorted into quintiles based on beta. Q1 is the portfolio of stocks with the highest quintile of beta. Rest of the table report the return differences of portfolio terciles (q1 is the highest terciles) formed monthly for other subcategories. Return and alpha spreads and their Newey-West [39] t-statistics are reported with $5 \%$ or higher significance in boldface. BETA is computed using daily returns over the past month.

\begin{tabular}{|c|c|c|c|c|c|c|c|c|c|}
\hline \multirow[t]{2}{*}{ Sorted by Beta } & \multirow[t]{2}{*}{ All stocks } & \multicolumn{2}{|l|}{ Size } & \multicolumn{2}{|c|}{ Book-to-Market } & \multicolumn{2}{|l|}{ Beta } & \multicolumn{2}{|c|}{ Momentum } \\
\hline & & Small & Large & Low & High & Low & High & Low & High \\
\hline $\mathrm{q1/Q1}$ & $0.65 \%$ & $1.09 \%$ & $0.20 \%$ & $0.19 \%$ & $0.95 \%$ & $0.63 \%$ & $0.61 \%$ & $0.96 \%$ & $1.05 \%$ \\
\hline $\mathrm{q} 2 / \mathrm{Q} 2$ & $1.38 \%$ & $1.65 \%$ & $0.23 \%$ & $0.49 \%$ & $0.75 \%$ & $1.62 \%$ & $0.40 \%$ & $0.60 \%$ & $0.63 \%$ \\
\hline q3/Q3 & $1.05 \%$ & $15.52 \%$ & $0.45 \%$ & $0.28 \%$ & $0.99 \%$ & $1.60 \%$ & $3.28 \%$ & $0.56 \%$ & $2.34 \%$ \\
\hline Q4 & $0.40 \%$ & & & & & & & & \\
\hline Q5 & $2.79 \%$ & & & & & & & & \\
\hline q3-q1/Q5-Q1 & $2.14 \%$ & $14.59 \%$ & $0.22 \%$ & $0.08 \%$ & $0.01 \%$ & $1.01 \%$ & $2.72 \%$ & $-0.42 \%$ & $1.26 \%$ \\
\hline t-stat & 1.85 & 1.84 & 0.70 & 0.30 & 0.04 & 0.93 & 2.13 & -0.59 & 1.39 \\
\hline alpha & $0.48 \%$ & $13.68 \%$ & $0.15 \%$ & $0.04 \%$ & $-0.36 \%$ & $0.05 \%$ & $1.17 \%$ & $-0.13 \%$ & $0.36 \%$ \\
\hline t-stat & 0.47 & 1.68 & 0.47 & 0.16 & -0.96 & 0.05 & 1.04 & -0.19 & 0.41 \\
\hline
\end{tabular}

Table 5 reports the average beta and idiosyncratic volatility values for the quintiles. MAX(1) is based on maximum daily return over the past one month and $\operatorname{MAX}(5)$ is based on highest five daily returns over the past one month. Quintile 1 is the low MAX, and quintile 5 is the high MAX.

Table 5A. Lottery like stocks - MAX(1) and $\operatorname{MAX}(5)$ and average quintile values

\begin{tabular}{l|l|l|l|l}
\hline Factor & Quintile & MAX & Beta & Idiosyncratic Vol. \\
\hline & 1 & -0.09 & 0.086 & 0.0018 \\
\hline & 2 & 0.12 & 0.07 & 0.0027 \\
\hline $\operatorname{MAX}(1)$ & 3 & 1.49 & 0.536 & 0.0071 \\
\hline & 4 & 3.33 & 1.264 & 0.0125 \\
\hline & 5 & 13.73 & 2.834 & 0.0282 \\
\hline & 1 & -0.13 & 0.087 & 0.0018 \\
\hline & 2 & 0.03 & 0.056 & 0.0027 \\
\hline $\operatorname{MAX}(5)$ & 3 & 0.58 & 0.292 & 0.0072 \\
\hline & 4 & 1.62 & 1.188 & 0.0127 \\
\hline & 5 & 4.86 & 3.161 & 0.0282
\end{tabular}

Table 5A highlights the average beta and idiosyncratic volatility values per lottery factor quintile. It shows that higher lottery factor quintiles have both higher beta and idiosyncratic risk averages. As we move the quintile 1 to quintile 5 in $\mathrm{MAX}(1)$, the average across the months of the mean daily maximum returns of the stocks increases from $-0.09 \%$ to $13.73 \%$. Based on that we can one can conclude that in Santiago Stock Exchange, the lottery factor should be highly correlated to beta and idiosyncratic volatility. This result is very similar to the one demonstrated by Bali et al. [6].

Table 5B shows that when stocks are evaluated as a whole, using the lottery factors MAX(1) as the sorter, we have approximately $-7 \%$ monthly return differences with a t-value of 1.34 . However, when lottery factors are used as the sorting factor and stocks further sorted as low and high beta, we observe statistically and economically significant results ${ }^{10}$. Risk adjusted alpha values for low and high beta sets are also statistically and economically significant. Table 5B provides us with important insights: As expected, high-beta (low-beta) stocks are providing high (low) excess returns. Also in line with Bali et al. [6], our portfolio level analysis indicates a negative and significant relation between the maximum daily

\footnotetext{
${ }^{10}$ High fluctuations in returns in terciles may be attributable to serious amount of illiquidity and significant price
} movement of some stocks. 
return over the past one month (MAX) and expected stock returns.

Table 5B. Lottery like stocks - MAX(1). All-stocks column reports the equal-weighted portfolio quintile returns formed monthly from January 2007 to January 2016, sorted into quintiles based on maximum daily return over the past one month, MAX(1) Q1 is the portfolio of stocks with the highest quintile of $\operatorname{MAX}(1)$. Rest of the table report the return differences of portfolio terciles ( $\mathrm{q} 1$ is the highest terciles) formed monthly for low and high betas and low and high idiosyncratic volatilities. Return and alpha spreads and their Newey-West [39] t-statistics are reported with $5 \%$ or higher significance in boldface.

\begin{tabular}{l|l|l|l|l|l}
\hline MAX(1) & All stocks & \multicolumn{2}{l|}{ Beta } & \multicolumn{2}{l}{ Idiosyncratic Risk } \\
\hline & & Low & High & Low & High \\
\hline Q1/q1 & $7.85 \%$ & $-0.48 \%$ & $-0.17 \%$ & $-0.17 \%$ & $-4.08 \%$ \\
\hline Q2/q2 & $0.58 \%$ & $-0.66 \%$ & $0.28 \%$ & $-0.14 \%$ & $0.74 \%$ \\
\hline Q3/q3 & $1.11 \%$ & $1.99 \%$ & $15.41 \%$ & $0.67 \%$ & $13.13 \%$ \\
\hline Q4 & $0.81 \%$ & & & & \\
\hline Q5 & $0.86 \%$ & & & & \\
\hline Q5-Q1/q3-q1 & $-6.99 \%$ & $\mathbf{2 . 4 8 \%}$ & $\mathbf{1 8 . 3 3 \%}$ & $\mathbf{0 . 8 4 \%}$ & $\mathbf{1 7 . 2 2 \%}$ \\
\hline t-stat & -1.34 & $\mathbf{8 . 9 4}$ & $\mathbf{3 . 0 2}$ & $\mathbf{6 . 8 7}$ & $\mathbf{3 . 2 5}$ \\
\hline alpha & $-1.18 \%$ & $\mathbf{1 . 7 7 \%}$ & $\mathbf{9 . 8 4 \%}$ & $\mathbf{0 . 3 8 \%}$ & $\mathbf{1 0 . 1 8 \%}$ \\
\hline t-stat & -0.25 & $\mathbf{7 . 3 2}$ & $\mathbf{1 . 9 3}$ & $\mathbf{3 . 2 3}$ & $\mathbf{2 . 2 2}$ \\
\hline
\end{tabular}

\subsection{Idiosyncratic Volatility}

In classic CAPM model, since investors hold efficiently diversified portfolios, the idiosyncratic risk is not priced. As a result, it seems not meaningful to use the idiosyncratic risk to predict the returns. However, as Xu and Malkiel [51] explained, investment managers will often structure their portfolios deliberately to accept the considerable idiosyncratic risk to obtain extraordinary returns. In a widely cited paper, Ang et al. [1] find a strong negative relation between idiosyncratic volatility and future stock returns. The result was highly inconsistent with the predictions of many theoretical models and consequently called as the idiosyncratic volatility puzzle.

Bali and Cakici [4] demonstrate that among the other things, data frequency, portfolio weighting scheme, and portfolio breakpoint calculation methodology, all have substantial impacts on the idiosyncratic volatility puzzle. Several subsequent papers have proposed explanations for the idiosyncratic volatility puzzle: Huang et al. [31] showed that the negative relation is driven by the shortterm reversal phenomenon. Han and Lesmond [29] provide evidence that the idiosyncratic volatility puzzle is a manifestation of liquidity shocks. Bali, Cakici, and Whitelaw [6] find that after controlling for demand for lottery-like stocks, the negative relation between idiosyncratic volatility and future stock returns disappears, and in some analyses becomes positive.

We find a positive but insignificant relation between idiosyncratic volatility and future returns on individual stocks trading in Santiago Stock Exchange. This finding is consistent with Bali and Cakici [4] and Bali and Hovakimian [5] who provide similar evidence for the US equity market. In summary, our results demonstrate the absence of idiosyncratic volatility puzzle in Santiago Stock Exchange.

In summary, our risk-related indicators, the total volatility, beta, and idiosyncratic volatility produced generally ineffective results ${ }^{11}$. In all-stocks sets, there were no statistically significant results at the usual $5 \%$ level. The highest level of statistical significance in risk-related set is obtained when the sorting is done with beta, and its value is 2.14 percent for the raw return differences with a t-value of 1.85 . The other exception is high-beta set: when the high-beta stocks are grouped together, total volatility, idiosyncratic volatility, and the beta yield statistically and economically significant raw return differences. The coefficient values are $2.83 \%, 2.72 \%$, and $2.74 \%$ for total volatility, beta, and idiosyncratic volatility, with the t-values of 2.10, 2.13, and 2.03, respectively. As a result, we can say that, in Santiago Stock Exchange, the risk related predictors are effective only in predicting future high-beta stock returns.

\footnotetext{
${ }^{11}$ The risk related results are not effective for 7 out of 8 subcategories
} 
Table 6. Idiosyncratic volatility. All-stocks column reports the equal-weighted portfolio quintile returns formed monthly from January 2007 to January 2016, sorted into quintiles based on idiosyncratic volatility. Q1 is the portfolio of stocks with the highest quintile of idiosyncratic volatility. Rest of the table report the return differences of portfolio terciles (q1 is the highest terciles) formed monthly for other subcategories. Return and alpha spreads and their Newey-West [39] t-statistics are reported with $5 \%$ or higher significance in boldface. Beta and idiosyncratic volatility are computed using daily returns over the past month.

\begin{tabular}{l|l|l|l|l|l|l|l|l|l}
\hline Sorted by SSE & All stocks & \multicolumn{2}{l}{ Size } & \multicolumn{3}{l|}{ Book-to-Market } & \multicolumn{2}{l|}{ Beta } & \multicolumn{2}{l}{ Momentum } \\
\cline { 3 - 11 } & & Small & Large & Low & High & Low & High & Low & High \\
\hline q1/Q1 & $1.18 \%$ & $1.07 \%$ & $0.24 \%$ & $0.35 \%$ & $0.85 \%$ & $1.40 \%$ & $0.65 \%$ & $0.46 \%$ & $0.93 \%$ \\
q2/Q2 & $0.70 \%$ & $1.74 \%$ & $0.26 \%$ & $0.62 \%$ & $0.63 \%$ & $1.41 \%$ & $0.25 \%$ & $1.14 \%$ & $0.63 \%$ \\
q3/Q3 & $1.13 \%$ & $2.15 \%$ & $0.39 \%$ & $0.18 \%$ & $0.95 \%$ & $0.64 \%$ & $3.34 \%$ & $1.04 \%$ & $2.34 \%$ \\
Q4 & $0.22 \%$ & & & & & & & & \\
Q5 & $3.03 \%$ & & & & & & & & \\
\hline q3-q1/Q5-Q1 & $1.85 \%$ & $1.03 \%$ & $0.18 \%$ & $-0.19 \%$ & $0.03 \%$ & $-0.80 \%$ & $\mathbf{2 . 7 4 \%}$ & $0.56 \%$ & $1.40 \%$ \\
t-stat & 1.64 & 1.39 & 0.52 & -0.63 & 0.05 & -0.99 & $\mathbf{2 . 0 3}$ & 0.74 & 1.43 \\
\hline alpha & $0.53 \%$ & $-0.11 \%$ & $0.01 \%$ & $-0.44 \%$ & $-0.19 \%$ & $-0.59 \%$ & $1.28 \%$ & $-0.28 \%$ & $0.43 \%$ \\
t-stat & 0.49 & -0.17 & 0.04 & -1.58 & -0.36 & -0.72 & 1.05 & -0.41 & 0.46 \\
\hline
\end{tabular}

As we can see in Table 9, the signs are consistently positive for all three risk-related predictors, for high-beta stocks. The effectiveness of risk-related predictors in equity return predictions do not in general presents a consistency. If we compare the results obtained in this section with the results reported by Cakici and Topyan [8] we see that Chile's results with no statistical significance are in line with the results for Malaysia, Philippines, Taiwan, and Thailand while they are in conflict with the results obtained for China, India, Indonesia, and Korea. It is however worth noting the effective results obtained for the high-beta sets in Chile.

\subsection{Idiosyncratic Volatility}

As another well-documented market anomaly, short-term reversal is defined as the previous month's return of the same stock. The effect is explained either as the reflection of the investors' initial price overreaction (Subrahmanyam [46] or as the price pressure connected to liquidity shocks (Pastor, Stambaugh, [40]). However, Da, Liu, and Schaumburg [19] report that short-term return reversal is much greater than previously documented and is driven by investor overreaction on the short side and liquidity shocks on the long side. Wei and Yang [50] relate the effectiveness of short- term reversal to the volatility and show that short-term reversal requires low volatility and does not exist for small or large stocks when volatilities are high.

Table 7 summarizes our findings on short-term reversal: we have a very significant negative effect of short-term reversal on both raw and risk-adjusted returns in all stocks set as well as five other subgroups. The raw return and risk-adjusted return differences for all stocks are $-4.37 \%$ and $-3.61 \%$ with tvalues of -4.27 and -3.97 , respectively. The results have the highest economic and statistical significance we reported in the paper. Sorting with a short-term reversal in small stocks set yields $-3.79 \%$ raw return, and $-3.03 \%$ risk-adjusted return differences with t-values of -4.07 and -3.81 , respectively. Large stocks sets, however, have no statistical significance. High-book-to- market stocks, when sorted by short-term reversal, produce $-1.49 \%$ raw return, and $-1.18 \%$ risk-adjusted return differences with t-values of -2.70 and -2.18 , respectively. Low-book-to-market stocks do not have statistical significance. While high beta stocks present very significant results with $-3.38 \%$ raw return and $-2.52 \%$ risk-adjusted return differences with t-values of -2.90 and -2.26 , respectively, the low-beta stocks do not have statistical significance. On the momentum side, we see no clear difference in low or high momentum sets. Raw return differences are $-2.65 \%$ and $-2.59 \%$ for the low and high-momentum stocks with the t-values of -2.55 and -2.59 , respectively. Risk-adjusted returns have lower economic significance with -1.72 and -1.90 for the low and high momentum sets and borderline statistical significance with -1.77 and -1.99 t-values.

Table 7. Short-term reversal. All-stocks column reports the equal-weighted portfolio quintile returns formed 
monthly from January 2007 to January 2016, sorted into quintiles based on short-term reversal. Q1 is the portfolio of stocks with the highest quintile of short-term reversal. Rest of the table report the return differences of portfolio terciles ( $\mathrm{q} 1$ is the highest terciles) formed monthly for other subcategories. Return and alpha spreads and their Newey-West [39] t-statistics are reported with $5 \%$ or higher significance in boldface. BETA is computed using daily returns over the past month.

\begin{tabular}{|c|c|c|c|c|c|c|c|c|c|}
\hline \multirow[t]{2}{*}{ Sorted by STREV } & \multirow[t]{2}{*}{ All stocks } & \multicolumn{2}{|l|}{ Size } & \multicolumn{2}{|c|}{ Book-to-Market } & \multicolumn{2}{|l|}{ Beta } & \multicolumn{2}{|c|}{ Momentum } \\
\hline & & Small & Large & Low & High & Low & High & Low & High \\
\hline q1/Q1 & $4.03 \%$ & $3.66 \%$ & $0.47 \%$ & $0.11 \%$ & $1.84 \%$ & $2.13 \%$ & $3.36 \%$ & $2.29 \%$ & $3.19 \%$ \\
\hline q2/Q2 & $0.51 \%$ & $0.77 \%$ & $0.34 \%$ & $0.39 \%$ & $0.96 \%$ & $0.97 \%$ & $0.95 \%$ & $0.11 \%$ & $0.92 \%$ \\
\hline q3/Q3 & $0.84 \%$ & $-0.08 \%$ & $0.31 \%$ & $0.29 \%$ & $0.34 \%$ & $0.35 \%$ & $0.02 \%$ & $-0.35 \%$ & $0.63 \%$ \\
\hline Q4 & $0.78 \%$ & & & & & & & & \\
\hline Q5 & $-0.34 \%$ & & & & & & & & \\
\hline q3-q1/Q5-Q1 & $-4.37 \%$ & $-3.79 \%$ & $-0.16 \%$ & $0.22 \%$ & $-1.49 \%$ & $-1.79 \%$ & $-3.38 \%$ & $-2.65 \%$ & $-2.59 \%$ \\
\hline t-stat & -4.27 & -4.07 & -0.39 & 0.56 & -2.70 & -1.60 & -2.90 & -2.55 & -2.59 \\
\hline alpha & $-3.61 \%$ & $-3.03 \%$ & $-0.05 \%$ & $0.34 \%$ & $-1.18 \%$ & $-0.80 \%$ & $-2.52 \%$ & $-1.72 \%$ & $-1.90 \%$ \\
\hline t-stat & -3.97 & -3.81 & -0.11 & 0.84 & -2.18 & -0.77 & -2.26 & -1.77 & -1.99 \\
\hline
\end{tabular}

This work shows that short-term reversal is a very important firm-level predictor with strong statistical significance and the highest economic significance we obtained for all and small stocks listed in Santiago Stock Exchange. This suggests that individual investors, as well as fund managers, should observe the "short-term reversal" closely for effective prediction of equity returns.

\subsection{Momentum}

As a widely studied and popular predictor, the momentum effect is simply the stock's recent performance history. It implies that the past loser will continue to lose and the past winner will continue to win. It is generally agreed that stock returns appear to exhibit momentum in the short and medium runs. (Hong and Stein [30]). Momentum also stays at the center of the market efficiency debate as many researchers use it as an indicator of market inefficiency. We, however, prefer to evaluate momentum's predictive power isolated from market efficiency issues. As underlined by Cochrane [16], risk is a complicated multidimensional matter and the empirical findings may indicate that the underlined factors, such as momentum, in reality may simply approximate some fundamental risks that require due compensation, and not necessarily due to market inefficiencies.

The existence of momentum may be explained by the over-reaction generated by human overconfidence. (DeBondt and Thaler [21]). Daniel et al. [20] interpret overconfidence as an overweighting of private information and consequent underweighting of public information in trading decisions. We found no statistically significant evidence that momentum predicts the stock returns in Chile when applied to all stocks set. Momentum, however, was the only statistically significant return predictor for the large stocks set! In addition, we observed the momentum effect in low book-to- market stocks. Those results are in line with the results obtained for several markets around the world. Cakici and Topyan [8] report that the momentum was a large-stock and low-book-to-market stock event for 6 out of 8 Asian emerging markets they studied.

Table 8 summarizes the effectiveness of momentum as the firm-level return predictor. The momentum did not produce any predictive power in all stocks set for raw or risk-adjusted returns. When used with large stocks, however, we have $1.18 \%$ raw return, and $1.16 \%$ alpha values, with t-values of 3.17 and 3.03 , respectively. This result suggests that momentum is simply a large stock predictor in Santiago Stock Exchange. Momentum is also effective in a low-book-to-market set with $0.75 \%$ raw and $0.81 \%$ riskadjusted return differences, with t-values of 2.05 and 2.18, respectively; suggesting it should be a useful return predictor in low-book-to-market stocks. In addition, momentum, as a firm-level predictor, also showed predictive power in high-momentum stocks, with $1.58 \%$ raw return difference with a t-value of 1.91 .

Table 8. Momentum. All-stocks column reports the equal-weighted portfolio quintile returns formed every month 
from January 2007 to January 2016, sorted into quintiles based on momentum. Q1 is the portfolio of stocks with the highest quintile of momentum. Rest of the table report the return differences of portfolio terciles (q1 is the highest terciles) formed monthly for other subcategories. Return and alpha spreads and their Newey-West [39] t-statistics are reported with $5 \%$ or higher significance in boldface. BETA is computed using daily returns over the past month.

\begin{tabular}{|c|c|c|c|c|c|c|c|c|c|c|}
\hline \multirow{2}{*}{$\begin{array}{l}\text { Sorted } \\
\text { Momentum }\end{array}$} & \multirow[t]{2}{*}{ by } & \multirow[t]{2}{*}{ All stocks } & \multicolumn{2}{|l|}{ Size } & \multicolumn{2}{|c|}{ Book-to-Market } & \multicolumn{2}{|l|}{ Beta } & \multicolumn{2}{|c|}{ Momentum } \\
\hline & & & Small & Large & Low & High & Low & High & Low & High \\
\hline $\mathrm{q1} / \mathrm{Q1}$ & & $1.28 \%$ & $1.30 \%$ & $-0.11 \%$ & $-0.13 \%$ & $0.98 \%$ & $1.30 \%$ & $0.99 \%$ & $1.39 \%$ & $0.56 \%$ \\
\hline q2/Q2 & & $0.36 \%$ & $1.12 \%$ & $1.06 \%$ & $0.52 \%$ & $1.04 \%$ & $0.66 \%$ & $0.42 \%$ & $0.56 \%$ & $2.06 \%$ \\
\hline q3/Q3 & & $0.43 \%$ & $2.23 \%$ & $1.02 \%$ & $0.66 \%$ & $1.40 \%$ & $0.87 \%$ & $2.97 \%$ & $0.32 \%$ & $2.14 \%$ \\
\hline Q4 & & $1.56 \%$ & & & & & & & & \\
\hline Q5 & & $2.05 \%$ & & & & & & & & \\
\hline q3-q1/Q5-Q1 & & $0.77 \%$ & $0.89 \%$ & $1.18 \%$ & $0.75 \%$ & $0.45 \%$ & $-0.43 \%$ & $1.96 \%$ & $-1.03 \%$ & $1.58 \%$ \\
\hline t-stat & & 0.70 & 0.89 & 3.17 & 2.05 & 0.86 & -0.40 & 1.47 & -1.12 & 1.91 \\
\hline alpha & & $0.89 \%$ & $0.40 \%$ & $1.16 \%$ & $0.81 \%$ & $0.76 \%$ & $0.33 \%$ & $1.61 \%$ & $-0.01 \%$ & $0.95 \%$ \\
\hline t-stat & & 0.81 & 0.39 & 3.03 & 2.18 & 1.51 & 0.33 & 1.18 & -0.02 & 1.19 \\
\hline
\end{tabular}

Table 9. Sign consistency for statistically significant predictors. Table displays the signs of raw return differences for all stocks and other subgroups for statistically significant predictors at 5 percent level or better. Size, book-to-market, earnings-to-price, and short-term reversal are consistently important predictors for all stocks as well as many subgroups, while momentum, beta, total volatility, and idiosyncratic volatility are selectively important in certain subgroups. Signs show no inconsistency at all.

\begin{tabular}{|c|c|c|c|c|c|c|c|c|c|}
\hline & \multicolumn{9}{|c|}{ Signs of Portfolio Method Raw Return Differences } \\
\hline & $\begin{array}{l}\frac{n}{3} \\
0 \\
0 \\
i n \\
\equiv \\
\end{array}$ & 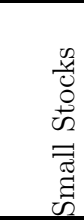 & 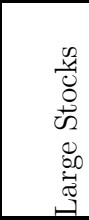 & 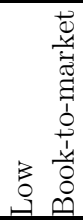 & 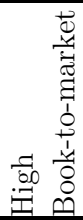 & $\begin{array}{c}\frac{\pi}{0} \\
0 \\
0 \\
0 \\
0 \\
1\end{array}$ & $\begin{array}{l}\frac{\pi}{0} \\
0 \\
0 \\
010 \\
010\end{array}$ & 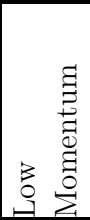 & 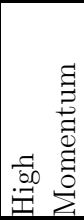 \\
\hline SIZE & - & - & & & - & - & - & - & - \\
\hline BKTM & + & + & & & + & & & + & + \\
\hline $\mathrm{EP}$ & + & + & & + & + & + & & & + \\
\hline SD & & & & & & & + & & \\
\hline SSE & & & & & & & + & & \\
\hline BETA & & & & & & & + & & \\
\hline STREV & - & - & & & - & & - & - & - \\
\hline MOM & & & + & + & & & & & + \\
\hline
\end{tabular}

Table 9 reports the signs of raw return differences and highlights the consistency obtained. If it is statistically significant, signs attributed to firm-level predictors never change for sub-categories. Starting with all stocks set the signs obtained from the portfolio method never alters for the controlled categories. Obtained signs are perfectly in line with the literature as the size and short-term reversal have the negative signs, implying they move in opposite direction with stock returns, for all statistically significant categories. Momentum, earnings-to-price, and book-to-market have the positive signs in all categories. Similarly, in the risk-related predictors set, total volatility, beta, and idiosyncratic volatility 
have the positive signs, although they are statistically significant only in one sub-category.

Our study highlights large-stock returns as the most difficult to predict. Seven of our eight firm-level predictors consistently failed to produce statistically significant results. Large-stocks, however, have a very significant momentum effect. Similarly, momentum failed to show statistical significance in 6 out of 8 categories, it was noted as the only firm-level indicator that successfully predicts the large-stock returns. Momentum is also statistically significant in the low book-to-market set. The risk-related predictors turned out not predictable when sorted by total volatility, idiosyncratic volatility, and beta in high-book-to-market, low-beta, and low momentum sets.

As for the cheapness variables, book-to-market, and earnings-to-price ratios produced the highest consistency in terms of sub-category predictability. We have statistically significant results in every category except, large-stocks and high-beta stocks. Size, also as expected, yielded statistically and economically significant powerful predictive power except for large-stocks and low book-to-market stocks. Short-term reversal turned out a powerful predictor and produced statistically and economically significant results in every category except large stocks and low book-to-market stocks while momentum turned out statistically significant only for the large and low book-to- market stocks.

\section{Conclusion}

This paper evaluates the equity returns predictability in Santiago Stock Exchange, Chile, using portfolio method and reports the predictive powers of commonly used firm-level attributes such as book-market ratio, size, earnings-to-price ratio, total risk, beta, idiosyncratic risk, short-term reversal, and momentum. The paper's other goal is to relate and compare the predictive powers of Chilean firm-level variables with the previous studies covering other markets. With these goals in mind, we analyzed the stock return predictability using the stocks listed in Santiago Stock Exchange covering the period from January 2007 to January 2016. Using portfolio method with monthly data, we showed the impressive predictive powers of our cheapness variables, book-to-market ratio, and earnings-to-price ratios, as expected and in line with the surveyed literature. We confirmed their predictive powers for Chile, economically and statistically, for both raw and risk-adjusted return differences. The only two subcategories they failed to show statistical significances were the large caps and high beta stocks and this needs to be highlighted as an important difference observed in Chilean equity markets.

Chile presents impressive similarities to the other emerging markets throughout the world with its reliable cheapness variables as effective future equity return predictors and their large-caps are the least predictable stocks. The predictive power of market capitalization was also in line with the literature as it was statistically and economically significant for all but two subcategories: large caps and low bookto-markets. The momentum has the predictive power only in large-caps and low-book-to-market stocks.

Total volatility, idiosyncratic volatility, and beta failed to show any statistically significant predictive powers. The only statistical significance we observed was for the raw return differences and in the set of high-beta stocks. When all stocks are included, the predictors showed some statistical significance in raw returns with t-values $1.65,1.85$, and 1.64 for total volatility, beta, and idiosyncratic volatility, respectively. Their economic significance, however, quite high and around $2 \%$ raw return difference per month. Total volatility, idiosyncratic volatility, and beta traditionally providing the researchers with mixed signals as firm-level return predictors. For instance, in Cakici and Topyan [8] those variables were not statistically or economically significant in 5 out of 8 Asian emerging market countries.

An important distinction in Chilean financial market is the relative effectiveness of short-term reversal. Short-term reversal showed an impressive predictive power for all- stocks, small-caps, high-book-tomarket and high-beta stocks for both raw and risk- adjusted returns; statistically and economically.

Finally, those results can effectively be used by portfolio manager dealing with stocks listed in Santiago Stock Exchange. However, it should be noted that for effective use of the information by portfolio managers, one needs to have return differences that are higher than any reasonable transaction cost estimates. Managers find it more difficult to benefit the results obtained from firm-level portfolio method if they have to trade the stocks too frequently. Therefore, an important question of whether these variables can predict the return beyond the first month should be asked and evaluated. 


\section{References}

1. A. Ang, R. J. Hodrick, Y. Xing, and X.Zhang, "The Cross-Section of Volatility and Expected Returns," Journal of Finance, vol. 61, pp. 259-299, 2006.

2. R. K. Arora, H. Das, and P. K. Jain, "Stock Returns and Volatility: Evidence from Select Emerging Markets," Review of Pacific Basin Financial Markets and Policies, vol. 12, pp. 567-592, 2009.

3. C. S. Asness, T. J. Moskowitz, and L. H. Pedersen, "Value and Momentum Everywhere," Journal of Finance, vol. 68, pp. 929-985, 2013.

4. T. G. Bali and N. Cakici, "Idiosyncratic Volatility and the Cross Section of Expected Returns," Journal of Financial and Quantitative Analysis, vol. 43, pp. 29-58, 2008.

5. T. G. Bali and A. Hovakimian, "Volatility Spreads and Expected Stock Returns," Management Science, vol. 55, pp. 1797-1812, 2009.

6. T. G. Bali, N. Cakici, and R. F. Whitelaw, "Maxing Out: Stocks as Lotteries and the Cross-Section of Expected Returns," Journal of Financial Economics, vol. 99, pp. 427-446, 2011.

7. T. G. Bali, S. J. Brown, S. Murray, and Y. Tang, "A Lottery Demand-Based Explanation of the Beta Anomaly," Journal of Financial and Quantitative Analysis, Forthcoming, 2016.

8. N. Cakici and K. Topyan, Risk and Return in Asian Emerging Markets. Palgrave, MacMillan, 2014.

9. J. Campbell and R. Shiller, "Stock Prices, Earnings, and Expected Dividends," Journal of Finance, vol. 43, pp. 661-676, 1988.

10.R. H. Campbell, "Predictable Risk and Returns in Emerging Markets," Review of Financial Studies, vol. 8, pp. 773-816, 1995.

11.K. Chan, A. Hameed, and W. Tong, "Profitability of Momentum Strategies in the International Equity," The Journal of Financial and Quantitative Analysis, vol. 35, pp. 153-172, 2000.

12.K. C. Chan and N. Chen, "Structural and Return Characteristics of Small and Large Firms," Journal of Finance, vol. 46, pp. 1467-1484, 1991.

13.K. C. Chan, Y. Hamao, and J. Lakonishok, "Fundamentals and Stock Returns in Japan," Journal of Finance, vol. 46, pp. 1739-1764, 1991.

14.N. Chen and F. Zhang, "Risk and Return of Value Stocks," Journal of Business, vol. 71, pp. 501-535, 1998.

15.N. Chopra, J. Lakonishok, and J. Ritter, "Measuring Abnormal Performance: Do Stocks Overreact?" Journal of Financial Economics, vol. 31, pp. 235-268, 1992.

16.J. Cochrane, "Financial markets and the real economy," in Handbook of the Equity Risk Premium, edited by R. Mehra. Elsevier Science, 2007.

17.J. Cochrane, "The Dog that did not Bark: A Defense of Return Predictability," Review of Financial Studies, vol. 21, pp. 1533-1575, 2008.

18.M. A. Crain, A Literature Review of the Size Effect, 2011, Available: http://ssrn.com/abstract=1710076 http://dx.doi.org/10.2139/ssrn.1710076

19.Z. Da, Q. Liu, and E. Schaumburg, "Decomposing Short-Term Return Reversal," Federal Reserve Bank of New York Staff Reports, no. 513, September 2011.

20.K. Daniel, D. Hirshleifer, and A. Subrahmanyam, "Investor Psychology and Security Market Under and Overreactions," Journal of Finance, vol. 53, pp. 1839-1886, 1998.

21.W. F. M. DeBondt and R. H. Thaler, "Financial Decision-Making in Markets and Firms: A Behavioral Perspective In Finance," Handbooks in Operations Research and Management Science, edited by R. Jarrow, V. Maksimovic, and W. Ziemba, vol. 9, chap. 13, pp. 385-410. Amsterdam: Elsevier, 1995.

22.C. Espinosa, F. Parisi, and A. Parisi, "Pruebas de Comportamiento Caótico en Indices Bursátiles Americanos," El Trimestre Económico, vol. 74, pp. 901-927, 2007.

23.E. Fama and K. R. French, "Dividend Yields and Expected Stock Returns," Journal of Financial Economics, vol. 22, pp. 3-25, 1988.

24.E. Fama and K. R. French, "The Cross-Section of Expected Stock Returns," Journal of Finance, vol. 47, pp. 427466, 1992.

25.E. Fama and K. R. French, "Value versus growth: The international evidence," Journal of Finance, vol. 53, pp. 1975-1999, 1998. 
26.E. Fama and J. MacBeth, "Risk, Return, and Equilibrium: Empirical Tests," Journal of Political Economy, vol. 81, pp. 607-636, 1973.

27.R. S. Fuentes, J. Gregoire, and S.L. Zurita, "Factores Macroeconómicos en Rendimientos Accionarios Chilenos," El Trimestre Económico, vol. 73, pp. 125-138, 2006.

28.B. D. Grundy and S. Martin, "Momentum: Fact or Factor? Momentum Investing when Returns have a Factor Structure," Review of Financial Studies, vol. 14, pp. 29-78, 2001.

29.Y. Han and D. Lesmond, "Liquidity Biases and the Procong of Cross-Sectional Idiosyncratic Volatility," Review of Financial Studies, vol. 24, pp. 1590-1629, 2011.

30.H. Hong and J. Stein, "A Unified Theory of Underreaction, Momentum Trading and Overreaction in Asset Markets," Journal of Finance, vol. 54, pp. 2143-2184, 1999.

31.W. Huang, Q. Liu, S. G. Rhee, and L. Zhang, "Return Reversals, Idiosyncratic Risk, and Expected Returns," The Review of Financial Studies, vol. 23, pp. 147-168, 2010.

32.N. Jegadeesh, "Evidence of Predictable Behavior of Security Returns," Journal of Finance, vol. 45, pp. 881-898, 1990.

33.N. Jegadeesh and S Titman, "Returns to Buying Winners and Selling Losers: Implications for Stock Market Efficiency," Journal of Finance, vol. 48, pp. 65-91, 1993.

34.G. Jiang, D. Li, and G. Li, "Capital Investment and Momentum Strategies," Review of Quantitative Finance and Accounting, vol. 39, pp. 165-188, 2012.

35.S.P. Kothari and J. Shanken, "Book-to-Market, Dividend Yield, and Expected Market Returns: A Time-Series Analysis," Journal of Financial Economics, vol. 44, pp. 169-203, 1997.

36.J. Lakonishok, A. Shleifer, and R. Vishay, "Contrarian Investment, Extrapolation, and Risk," Journal of Finance, vol. 49, pp. 1541-1578, 1994.

37.B. N. Lehmann, "Fads, Martingales, and Market Efficiency," Quarterly Journal of Economics, vol. 105, pp. 1-28, 1990.

38.W. Liu, "A Liquidity-Augmented Capital Asset Pricing Model," Journal of Financial Economics, vol. 82, pp. 631-671, 2006.

39.W. K. Newey and K. D. West, "A Simple, Positive Semi-definite, Heteroskedasticity, and Autocorrelation Consistent Covariance Matrix," Econometrica, vol. 55, pp. 703-708, 1987.

40.L. Pastor and R. F. Stambaugh, "Liquidity Risk and Expected Stock Returns," Journal of Political Economy, vol. 111, pp. 642-685, 2003.

41.M. Pincus, S. Rajgopal, and M. Venkatachalam, "The Accrual Anomaly: International Evidence," Accounting Review, vol. 82, pp. 169-203, 2007.

42.K. G. Rouwenhorst, "International Momentum Strategies," Journal of Finance, vol. 53, pp. 267-324, 1998.

43.K. G. Rouwenhorst, "Local Return Factors and Turnover in Emerging Stock Markets," Journal of Finance, vol. 54, pp. 1439-1464, 1999.

44.T. R. A. Sapp, "The 52-Week High, Momentum, and Predicting Mutual Fund Returns," Review of Quantitative Finance and Accounting, vol. 37, pp. 149-179, 2011.

45.M. Scholes and J. Williams, "Estimating Betas from Nonsyncronious Data," Journal of Financial Economics, vol. 5, pp. 309-327, 1977

46.A. Subrahmanyam, "Distinguishing between Rationals for Short-Horizon Predictability of Stock Returns," Financial Review, vol. 40, pp. 11-35, 2005.

47.S. Titman, J. Wei, and F. Xie, "Capital Investments and Stock Returns," Journal of Financial and Quantitative Analysis, vol. 39, pp. 677-700, 2004.

48.E. Walker, "Predictibilidad-de-Rendimientos-en-el-Mercado-Accionario-Chileno," El Trimestre Económico, vol. 67, pp. 355-394, 2000.

49.Y. Wu, "Momentum Trading, Mean Reversal and Overreaction in Chinese Stock Market," Review of Quantitative Finance and Accounting, vol. 37, pp. 301-323, 2011.

50.J. Z. Wei and L. Yang, "Short-Term Momentum and Reversals in Large Stocks," (May 9, 2012). Available: https://ssrn.com/abstract=2029984 or http://dx.doi.org/10.2139/ssrn.2029984.

51.Y. Xu and B. G. Malkiel, "Investigating the Behavior of Idiosyncratic Volatility," Journal of Business, vol. 76, pp. 613-644, 2003. 
52.G. Yen and C. F. Lee, "Efficient Market Hypothesis (EMH): Past, Present, and Future," Review of Pacific Basin Financial Markets and Policies, vol. 11, pp. 305-329, 2008.

53.S. Yu, "New Empirical Evidence on the Investment Success of Momentum Strategies Based on Relative Stock Prices," Review of Quantitative Finance and Accounting, vol. 39, pp. 105-121, 2012. 